DOI: 10.11606/issn.2318-8855.v7i7p309-322

\title{
Richard Wagner e a Idade Média'
}

Jaqueline Uzai Tavares*

Resumo: Este ensaio tem como objetivo demonstrar as concepções do compositor Richard Wagner presentes na obra $A$ arte e a revolução e em sua mais famosa ópera $O$ Anel do Nibelungo acerca da Idade Média e de sua mitologia. Alinhado às ideais do romantismo alemão em voga no século XIX, Wagner constrói uma imagem idealizada e historicamente pouco precisa sobre os chamados povos germânicos e seus mitos. A despeito disso, porém, a extensão e a profundidade do impacto de Wagner na cultura contemporânea fazem que com que muitas dessas concepções ressoem, até hoje, no imaginário sobre a Idade Média.

Palavras-chave: Idade Média, Mitologia, Richard Wagner.

Winhelm Richard Wagner (1813-1883) é conhecido até os dias atuais como um dos mais influentes compositores eruditos de todos os tempos. Seu estilo influenciou diferentes áreas do estudo e composição artística (WHITTALL, 1995, p. 461-462). A forma única pela qual ele produziu suas óperas revolucionou completamente as apresentações do gênero e trouxe inúmeras inovações ao teatro, na construção de espetáculos nos quais Wagner trabalhou de maneira minuciosa, conectando cenário, narrativa e poesia. Além dessa esfera de produção artística direta, porém, o músico foi também um ensaísta que refletiu e escreveu extensamente sobre arte, tentando contemplá-la de um ponto de vista teórico, a partir de sua totalidade, tratando-a como elemento central de formação e reprodução da mentalidade e do comportamento de uma dada sociedade.

\footnotetext{
${ }^{1}$ Agradeço ao professor Marcelo Candido do Departamento de História por toda ajuda prestada na orientação do presente ensaio.

*Graduanda em História pela Faculdade de Filosofa, Letras e Ciências Humanas da Universidade de São Paulo. Contato: j.u.tavares@usp.br.
} 
Suas concepções sobre essa temática estavam alinhadas às ideias em circulação na época, derivadas do idealismo e do romantismo alemães. Ambos movimentos se preocupavam, sobretudo, com uma apreensão ampla e sensível da realidade através da introspecção, tomando a arte como importante parte desse processo, no qual a construção de uma chamada nova mitologia desempenha papel fundamental (HOLLINRAKE, 1995, p. 62), semelhante aquele que da mitologia clássica nas antigas civilizações. (STURMA, 1995, p. 2425). A essas preocupações, se somava também uma atenção em estudar, retomar e reconstruir as particularidades de cada povo, derivadas de sua língua, literatura e cultura próprias.

As obras de Wagner trazem consigo muitas dessas características. Em termos de forma, seu estilo particular de compor e produzir integrava música, cenário, história e interpretações. Em termos de temática, a representação de uma mitologia dada como germânica, pagã, resultado convergente de uma série de inspirações e reinterpretações literárias diferentes são em muitos sentidos a tentativa de recriar e glorificar o passado de um povo. O que Wagner buscava era um trabalho grandioso, impactante, uma obra de arte total, tanto do ponto de vista estético quanto social.

O processo de criação artística e sua função social são assuntos de grande interesse para Wagner e se encontram frequentemente presentes em seus textos. Há um estudo consciente sobre o próprio trabalho, que explicitamente analisa e considera quais devem ser suas características estéticas e seu papel na sociedade. Há, de fato, um projeto, dentro do qual uma mitologia dita medieval consiste em uma das principais fontes de inspiração. As obras artísticas resultantes dessa combinação penetraram no imaginário, ressoando até hoje.

Para compreender tais ressonâncias, porém, é necessário traçar o sentido que suas obras assumiram à sua própria época. Há duas facetas políticas oriundas de seu trabalho que eram elementos fundantes dos debates estabelecidos pelo músico com os contemporâneos interessados em suas obras. A primeira delas considera o trabalho de Wagner como uma tentativa de resgate de uma arte pura que demanda, em sua construção, a negação da arte 


\section{ensaios}

Richard Wagner e a Idade Média

moderna como entretenimento descartável. A revolução da arte depende da superação da modernidade e das amarras que esta impõe à criação artística. A inovação deve vir não apenas na medida do conteúdo das obras, mas também na forma que estas são apresentadas, na maneira que seus elementos são articulados internamente e no impacto que a arte deve exercer sobre a vida. O espetáculo deve tornar seu espectador um extemporâneo, que se desprende de si para apreciar a obra em sua totalidade, ao invés de encará-la como mera distração de seus tormentos, tal como era a arte moderna aos olhos do músico (NIETZSCHE, 2009, p. 39-40)².

O outro sentido político tomado pelas obras de Wagner na época de sua criação é a de símbolo nacionalista, que buscava resgatar e glorificar o espírito do povo a partir do passado e seus mitos, na tentativa de construção de um discurso legitimador para as nações em formação à época. A arte consiste em uma ferramenta de comunicação política, de uma tal maneira que uma filosofia estritamente científica não seria capaz de ser (BOWIE, 2008, p.240241). Décadas após a sua morte, a dimensão nacionalista do seu trabalho talvez tenha se tornado a mais persistente na memória, perpetuada em uma versão exacerbada e profundamente negativa através da reapropriação de sua obra pelo Partido Nazista e pela associação construída entre a ideologia e sua figura através deste movimento.

A despeito dessa imagem, porém, o impacto da figura e das obras de Richard Wagner sobre a cultura ocidental não se limitam a ela. As inovações artísticas trazidas pelos seus trabalhos, bem como as consequências filosóficas derivadas desta nova estética, permeiam a música e as artes cênicas contemporâneas. Citando apenas algumas de suas inovações na produção de óperas, destacam-se o uso da luzes em consonância com a música na composição da atmosfera de cena e o Leitmotiv (GREY, 1995, p. 259-260). A técnica pode ser definida como o uso de temas musicais específicos para ilustrar ou antecipar alguma

\footnotetext{
${ }^{2}$ Há limitações em se tratar as intepretações da arte de Wagner a partir de seus críticos e não diretamente de seus escritos. Nietzsche foi, porém, correspondente e a amigo íntimo do músico, ao menos durante parte de sua vida. Apesar das discordâncias posteriores e da complexidade desta relação que é, em si, um tópico extenso demais para ser tratado aqui com mais detalhes, a ideia de regeneração da cultura através de uma nova arte permanece um elemento constante no pensamento de ambos.
} 
situação, personagem ou emoção particular e, ainda que não tenha sido criada por Wagner, foi por ele aperfeiçoada. Hoje, esse é um recurso profundamente difundido, sobretudo na composição de trilhas sonoras, usado na construção cênica no cinema, no teatro e mesmo na televisão.

Dada essa introdução, apenas com objetivo de demonstrar de maneira panorâmica o impacto de Wagner, nos voltemos agora para os trabalhos que serão propriamente analisados aqui. A arte e revolução (1849), seu primeiro ensaio no qual ele estabelece considerações sobre arte e sociedade será o texto teórico analisado. Em paralelo, tomando-se uma das obras artísticas do músico, será trabalhado também o conteúdo O Anel do Nibelungo (1874), sua maior, mais famosa e mais influente ópera.

Começando então pelo ensaio, $A$ arte e revolução trata, em linhas gerais, de dois temas principais. Inicialmente, Wagner escreve sobre como os movimentos e agitações políticas do século XIX alteraram a realidade dos artistas. A partir de tal descrição, ele então sugere que a revolução poderia e deveria recriar a arte, trazendo como exemplos e antiexemplos para construção dessa nova realidade a arte de povos antigo e sua relação com suas respectivas sociedades. É neste movimento de comparação entre diferentes casos (ou, ao menos, entre as visões que Wagner tinha de cada um deles) que o texto se constrói.

A primeira e mais frequente aparição é a dos gregos, que são vistos de maneira muito elogiosa, como o verdadeiro ponto de origem histórico do desenvolvimento da arte na Europa (WAGNER, 2000, p. 37). No ápice da admiração de Wagner pela arte grega, encontrava-se o drama, definido por ele "[...] a mais elevada obra de arte que é possível conceber [...]" (WAGNER, 2000, p. 40). O autor argumenta que a grandiosidade do drama derivava de sua capacidade, ao mesmo tempo, de ser uma arte una, completa, e de expressar, criar e recriar o espírito do povo que a produz (WAGNER, 2000, p. 39-41). Wagner chega mesmo associar o declínio da tragédia como forma de arte a própria decadência do chamado Estado ateniense (WAGNER, 2000, p. 44). A arte e a sociedade como um todo estão, então, profundamente associadas. Sua ruína é conjunta. 


\section{ensaios}

\section{Richard Wagner e a Idade Média}

A arte usada como modelo ideal de inspiração é uma arte europeia, e sobretudo, pagã. Não apenas vinda de um povo pagão, mas cujas temáticas, que são destacadas por Wagner pela descrição dos rituais a Apolo contidas na obra, também o são (WAGNER, 2000, p. 38-41). O teatro tão elogiado pelo autor é sobretudo o que trata sobre mitologia que, não circunscrita apenas a uma esfera religiosa segregada, se articula com outros elementos culturais e ajuda a formar o próprio espírito do povo, e a reproduzi-lo através da construção de um Estado.

Esse posicionamento acerca da arte pagã grega se torna ainda mais evidente e relevante quanto contraposto à visão de Wagner sobre o Cristianismo. O tema aparece inicialmente quando o autor, depois de suas considerações acerca do mundo grego, segue cronologicamente e começa a dissertar sobre os romanos, vistos de maneira negativa, como um grupo de "brutais conquistadores" que, embora se inspirassem nos trabalhos gregos, não eram capazes de alcançar sua totalidade. Nesse conjunto, o Cristianismo é associado aos romanos, utilizado como mais um elemento para descrevê-los perniciosamente:

“[...] Arte é alegria de ser, é júbilo pela existência presente, pelo contexto geral a que se pertence, pelo contrário, nos finais do Império Romano vigorava o desprezo-próprio, a repulsa pelo caráter visível da existência, o horror face à sociedade. A expressão desse estado de coisas não podia ser, portanto, a arte. Tinha que ser o Cristianismo."[...] (WAGNER, 2000, p.48)

O Cristianismo é colocado como contraponto à arte. Não apenas isso, como algumas páginas adiante, é descrito como uma força negativa que moldou séculos da história humana, contra a qual todos aqueles que desejassem de fato produzir arte deveriam lutar. É nesse contexto que aparece a única menção direta de Wagner à Idade Média e a seus povos:

"[...] A hipocrisia é aliás o traço mais saliente, a fisionomia característica dos séculos cristãos até aos nossos dias. Um vício cada vez mais cruamente visível, cada vez menos envergonhado, à medida que a humanidade, apesar do Cristianismo, se ia refrescando na sua inextinguível fonte interior e amadurecia para o cumprimento de sua verdadeira tarefa. É tão forte a natureza, tão irreprimível sua permanente capacidade de gerar o novo, que não chega a ser possível imaginar uma violência que consiga enfraquecer-lhe a fertilidade. Nas veias enfermas do mundo romano veio a verter-se o sangue pleno de saúde e frescura das nações germânicas e, apesar da adopção do Cristianismo, os novos senhores do mundo conservaram o elemento de uma forte inclinação para a actividade, do desejo da empresa audaz, de uma autoconfiança sem 
peias. E ao longo da história da Idade Média, da mesma maneira que encontramos sempre como traço mais característico a luta do poder temporal contra o poder despótico da Igreja Romana, também a expressão artística desse mundo novo, sempre que procurava manifestar-se, tinha que se afirmar em contradição, em conflito com o espírito do Cristianismo.[...]" (WAGNER, 2000, p.52)

Desse enfático trecho de crítica ao Cristianismo e de exaltação às chamadas nações germânicas, é importante destacar a oposição desses dois elementos. Não há, em nenhum momento, uma convergência entre ambos: se há contato, é através de um conflito entre o poder da Igreja e o poder temporal. As tentativas de criação artística dos germânicos ocorrem apesar do Cristianismo, cujo espírito é contrário a tal tipo de expressão. Parece haver um descompasso, um conflito inconciliável, entre a religião hegemônica deste contexto e aqueles que nele viviam, sempre atuando, segundo o texto, apenas para combater esse controle.

Há, ainda, uma segunda contraposição, feita entre o mundo romano e o povos germânicos, que são descritos como um novo elemento de construção desse mundo, mas dotados de uma natureza diferente. A Idade Média para Wagner é constituída pela sobreposição destas duas culturas distintas, opostas por ele em uma caracterização profundamente valorativa. Há a parcela romana; ela é hegemônica, cristã e decadente. Sua antítese são os germânicos, que deveriam combatê-la, pertencendo a um mesmo contexto sem, porém, compartilhar com cristãos e romanos nada em comum. Não há, na cultura cristã, a penetração da religião no verdadeiro espírito do povo ou, pelo menos, não de maneira a gerar a partir desse contato uma arte digna deste nome.

Em si, os povos germânicos descritos por Wagner são, essencialmente, um conjunto homogêneo. Sem se reter às tentativas de descrevê-los com melhor detalhes, Wagner projeta sobre esses povos uma unidade que não sabemos se de fato existia, e que no entanto ele não parece em nenhum momento questionar. Tal homogeneidade consiste não apenas na coesão deste conjunto, mas tem como elemento central dessa uniformidade a sua oposição aos romanos e sua dissonância intrínseca aos preceitos cristãos. As pesquisas históricas realizadas para questionar a ideia de povos germânicos são posteriores a Wagner. O músico 


\section{ensaios}

Richard Wagner e a Idade Média

era um leitor ávido de literatura, filosofia e história, é de se pressupor, então, que ele estivesse alinhado com as concepções de sua época acerca da história germânica. Assim sendo, para as perspectivas contemporâneas ao ensaio, a construção do autor é aceitável.

É necessário ressaltar, porém, que esse alinhamento não consiste apenas em uma mesma base de chamados fatos históricos, mas também uma mesma visão política e ideológica acerca da função dos estudos e da memória sobre esses povos, suas culturas e mitologias. A aceitabilidade não implica apenas plausibilidade factual e interpretativa da construção narrativa do autor sobre este passado, como também um mesmo sentido pelo qual este conjunto é apropriado e tornado um recurso de legitimação de demandas nacionalistas em voga no século XIX. Ainda que o texto traga uma reflexão utópica e idealista sobre as funções da arte na sociedade através de exemplos históricos aparentemente distantes, há nesse ensaio um projeto engajado e profundamente conectado com as demandas do próprio tempo. E, ainda que Wagner se coloque como um crítico à mentalidade e à arte moderna, se projetando como um vanguardista que desejava quebrar os moldes que limitavam a produção artística de sua época, ela ainda se encontra preso às bases interpretativas nacionalistas, idealistas e românticas que são, historicamente, modernas.

Encerrando a análise interna do ensaio e considerando-o para a segunda fonte todas as reflexões de Wagner para a construção das próprias obras, podemos no reter agora a examinar a mais famosa delas. O Anel do Nibelungo é um conjunto de quatro óperas: Das Rheingold (O Ouro do Reno), Die Walküre (A Valquíria), Siegfried e Götterdämerung (Crepúsculo dos Deuses). As peças narram a história em torno de um anel de poder roubado do Rio Reno e as disputas por sua posse. Foi apresentado originalmente em 1874 no Teatro Bayreuth, construído por Wagner especialmente para abrigar suas óperas. O conjunto de obras foi anualmente reapresentado no local, que se tornou uma espécie de ponto peregrinação dos admiradores do trabalho do músico e um antro de nacionalismo, primeiro do próprio Império 
Alemão, depois do regime nazista. As reapresentações foram responsáveis pela perpetuação de sua fama, assim como também o foram o tamanho e a grandiosidade da ópera.

Não cabe aqui apreender todo o impacto da obra atualmente, mas é possível afirmar que suas redes de influência subterrâneas se estendem além do conhecimento explícito de suas origens. Em outras palavras, Wagner criou em $O$ Anel do Nibelungo conceitos e temas hoje incorporados à cultura popular e mais conhecidos do que a própria ópera e seu criador. Trechos de sua música foram repetidamente tocados em filmes ao ponto de ser tornarem reconhecidos - ainda que não nomeados pelo público. Os capacetes com chifres de seus figurinos foram incorporados ao imaginário dos nórdicos. Talvez o melhor exemplo desse legado seja a influência de sua releitura do mito do Anel do poder - que ressoa em um dos maiores best sellers e sagas cinematográficas dos séculos XX e XXI através de O Senhor dos Aneis, de J.R.R. Tolkien - justificando O Anel do Nibelungo como a maior obra de Richard Wagner, digna de ser melhor analisada.

Para tal, a versão aqui utilizada do texto é a transcrição feita por Andrew Porter. A ópera não consta em seu idioma original, o alemão; é uma tradução da obra para o inglês. Se tratando de uma peça musical, porém, o autor não teve como objetivo realizar uma tradução literal, mas sim uma que fosse capaz de considerar o sentido do texto com a musicalidade que ele deveria manter mesmo em outro idioma. Esse aspecto da fonte não é, contudo, influente para o que se pretende estudar aqui. A despeito de pequenas diferenças de vocabulário ou de sentido restrito de algumas palavras, o enredo e as temáticas do texto se mantém, e é neles, bem como em suas origens inspiracionais, que análise se retém.

A temática mitológica da obra fica clara já nas listas de personagens no início de cada ciclo: deuses, gigantes, deusas, valquírias. É uma obra pagã com personagens pagãos. Wagner, ávido leitor de uma chamada literatura medieval, se inspirou em quatro diferentes conjuntos de mitos medievais para a composição das peças: a Saga do Volsungos, a Saga Trideks, a Canção dos Nibelungos e a Edda Poética (FURNESS, 1995, p. 62). Há algumas 


\section{ensaios}

Richard Wagner e a Idade Média

considerações interessantes a se fazer sobre esses textos, utilizando como exemplo dois deles.

Não há uma única explicação para a origem da Edda Poética, e as versões apresentadas não são claras. Acredita-se, porém, que boa parte dos textos que sobreviveram até os dias atuais venha da Islândia, produzidos na ilha no período posterior a chegada do Cristianismo, que trouxe consigo o alfabeto na rúnico na qual estes foram escritos. (HOLLANDER, 1928, p. VII-XVIII). O material resultante é bastante fragmentado, e foi submetido a uma série de leituras, reconstruções e transposições, até chegar no século XIX. Um caminho parecido teve A canção dos Nibelungos. Escrita por volta de 1200 d.C, a origem das histórias remete aos séculos $\mathrm{V}$ e VI d.C, e foi recitada pela primeira vez na região que atualmente compreende a Áustria. O local em que ela foi escrita não é certo, e é provável que seus diversos registros derivem de regiões e datas diferentes (HATTO, p. 356-370, p. 396-401, 1969).

O que esse apanhado do histórico dos textos demonstra é que eles já tem, por si, uma origem muito nebulosa e incerta. Locais e datas precisos sobre esses registros não existem, assim como referências sobre qual subgrupo ou povo específico os escreveu. De fato, não há uma resposta única para essas questões porque, pelo que indicam os estudos (HATTO, p. 396-401, 1969), não existe apenas uma versão dessas obras. Sua trajetória, desde suas incertas origens, passa por uma série de modificações e transposições, até chegarem ao século XIX e serem resgatadas pelos românticos. À medida que esse material é inúmeras vezes reinterpretado pelas perspectivas desses leitores, mais ele se torna uma nova construção do que, de fato, um resgate da mitologia.

Em meio a esse histórico impreciso, a compreensão do sentido original dessa mitologia ou, em melhores termos, o entendimento de suas características e de sua relação com os povos específicos do período e da região em que primeiro estas foram contadas ou escritas se torna cada vez mais difícil. Pode-se chamar atenção, porém, para a relação que essa chamada mitologia pagã tinha com o Cristianismo, na qual o quadro parece ser mais complexo do que a mera oposição posta por Wagner. Não é possível saber somente com os 
textos em questão em que medida há o descompasso de mentalidades afirmado pelo músico, mas o contato entre as culturas dicotomizadas por Wagner parece ser parte importante para sua sobrevivência e reconstrução, a despeito das divergências que essas possam ter ou não. No caso da Edda Poética, por exemplo, o próprio registro escrito da narrativa se dá a partir do contato com a religião, e com o alfabeto trazido por ela. Não cabe dizer que tal registro só poderia ser feito de tal maneira, mas o evento atesta que havia contato entre o mundo pagão e o cristão, e que sua simbiose foi, em certos aspectos, parte do processo do registro de suas mitologias e da perpetuação de sua memória.

Tal imprecisão histórica não necessariamente frusta o projeto de Wagner, uma vez que seu trato com a mitologia não remete estritamente a uma tentativa de recriação precisa do passado, mas seu uso na construção de uma narrativa de impacto e de uma arte plena. Em parte, ao menos, ele obteve sucesso. Suas obras se tornaram parte integrante do imaginário existente sobre o medievo, a cultura e a mitologia nórdicas, e a memória construída sobre isso muitas vezes se confunde com a história.

Por outro lado há, porém, uma longa linha de reapropriações que cerca toda essa mitologia e o sentido de sua arte. Há as seleções realizadas pelos povos que as produziram e as conservaram ao longo dos séculos. Então, o recorte optado por aqueles que as leram no século XIX e as ressignificaram a mercê das próprias perspectivas e demandas. Finalmente, nos dias atuais, o desenrolar do mesmo processo, sob o julgo de uma outra mentalidade. A imagem mitológica do medievo formada carrega consigo todas essas camadas de reinterpretação, não necessariamente alinhadas umas às outras, mas sobrepostas. Compreender as formas pelas quais ocorre essa reapropriação e o que há de novo cada uma dessas camadas é parte do processo de entender o imaginário sobre o medievo atual, e como os usos políticos e culturais deste não estão sob efetivo controle das forças discursivas que o reconfiguravam e o legaram até o presente.

A Idade Média vista por Wagner é uma de conflito de forças. Há, no plano político, uma tradição cristã que tenta suprimir o que há de melhor na natureza humana e em seu 


\section{ensaios}

Richard Wagner e a Idade Média

potencial artístico. Ela não é plenamente capaz dessa tarefa, porém. Os povos germânicos consistem na oposição a essa força tão negativa. Eles são um conjunto coeso, contemporâneo aos romanos, mas brutalmente diferentes destes. Esses povos pagãos, cuja mitologia é um elemento de particular interesse, são capazes de tentar resistir ao poder e aos ideais cristãos. São esses os povos exaltados por Wagner, cuja imagem é formada a partir das informações disponíveis à época e configuradas de acordo com as perspectivas ideológicas e filosóficas daqueles que buscavam resgatá-las. A despeito da precisão histórica dessas construções, essas reapropriações ainda repercutem na memória contemporânea que, nem sempre atenta a esse processo de reconfiguração pelo qual as mitologias passam, encaram as obras românticas tais como as óperas de Wagner como medievais sem considerar a camada moderna presente nestas.

Uma última camada se coloca sobre esse emaranhado memorial, composta pela reinterpretação da obra do próprio Wagner e de seu legado, tão multifacetado e polêmico. Temos a mitologia medieval, sua reapropriação romântica e, finalmente, a perspectiva contemporânea acerca daqueles que a realizaram, criando uma linha temporal sobre esse legado memorial que extrapola o que poderia ser chamada da mitologia em si. O imaginário acerca do medievo não diz respeito apenas a ele; diz respeito a forma pela qual ele foi usado no século XIX para construção de narrativas nacionalistas, para se criar contos e óperas que, a despeito de sua inspiração no passado, eram profundamente carregados com questões do seu próprio tempo.

Essa ressignificação se estende até os dias atuais. Há modificações, porém, tanto na arte quanto na mitologia que ela perpetua. O conjunto possui traços contemporâneos que, sem neutralizar todas as camadas anteriores de reinterpretação memorial, adicionam a ela todo um novo sentido. As influências wagnerianas, sejam elas temáticas, musicais ou cenográficas, que permeiam a música, o teatro e o cinema, possuem sentidos próprios. Carregam, por um lado, a grandiosidade característica das obras do músico, capaz de coordenar diferentes elementos artísticos na criação de um conjunto único que absorve o expectador por inteiro. 
Talvez nada ilustre melhor essa totalidade englobante que tira o observador dos próprios olhos para transportá-lo a um novo mundo do que as salas de cinema. Pelo outro, representam o resgate do interesse por narrativas medievais, na ausência de termo melhor. De Wagner a Tolkien ao grande número de produções artísticas conectadas ao tema, elas refletem uma fascinação por toda essa medievalidade mas que, carrega, em cada caso, reinterpretações características do próprio tempo.

O impacto do trabalho do músico é profundo. As formas narrativas e os recursos sensoriais capitaneados por ele foram responsáveis pela construção de uma mais importantes formas de arte no mundo atual, que permeiam o imaginário e nos incutem virtudes e valores, ideais de beleza e grandiosidade e ajudam a formar nossas perspectivas sobre o mundo, ainda que de maneira parcial e muitas vezes inconsciente.

Isso não implica, porém, um impacto nos moldes aos quais Wagner o pensaria, de maneira a conectar o povo com o próprio espírito e negar a modernidade e sua arte alienante. Em primeiro lugar, porque as perspectivas contemporâneas sobre a nacionalidade são em muitos sentidos diferentes daquelas do século XIX. A despeito do poder do cinema na construção de narrativas que possam servir aos interesses das nações que os produzem, sua difusão é global. Sua tendência consiste mais na dissolução de fronteiras culturais a serviço das grandes potências produtoras do que em uma forma de proteção das chamadas culturas nacionais como um todo. Em segundo lugar, porque sua indústria é altamente capitalizada e os filmes consistem, entre outras coisas, em produtos de entretenimento. Se seu legado auxiliou na construção de novas formas de arte que, idealmente, influenciam na formação de nossas perspectivas de mundo, isso se dá em uma realidade que em muitos sentidos ainda carrega as características materiais de reprodução criticadas por Wagner.

A função desse exemplo bastante prosaico é, afinal das contas, ilustrar como o legado wagneriano se apresenta contemporaneamente, pensando-o em relação ao que poderia desejar seu criador. Por um lado, sua estética e sua forma reverberam em diferentes produções, ao mesmo tempo que as representações acerca Idade Média perpetuam-se em 


\section{ensaios}

Richard Wagner e a Idade Média

nosso imaginário. Pelo outro, o papel político e filosófico desta arte, bem como a forma pela qual ela é reproduzida e apropriada ainda trás muitas das características modernas que o músico tanto criticava. Wagner, afinal, teve profundo impacto na cultura, mas não o teve somente como quis.

\section{Fontes}

PORTER, A. [Tradução e Introdução]; WAGNER, R. The Ring of the Nibelung 1. ed. Londres: Faber Music Lta, 1976.

WAGNER, R. A arte e a revolução. 2. ed. Lisboa: Antígona, 2000.

\section{Referência bibliográficas}

BOWIE, A. German idealism and the arts. In: AMERIKS, K. [Organizador]. The Cambridge Companion to German Idealism. Cambridge: Cambridge University Press, 2008, p. 239-257

FURNESS, R. Panorama Intelectual: Literatura. In: MILLINGTON, B. [Organizador]. Wagner:um compêndio: Guia completo da música e da vida de Richard Wagner,. Rio de Janeiro: Jorge Zahar Editor, 1995, p. 62.

GREY, Thomar S. Um glossário Wagneriano. In: In: MILLINGTON, B. [Organizador]. Wagner: um compêndio: Guia completo da música e da vida de Richard Wagner,. Rio de Janeiro: Jorge Zahar Editor, 1995, p. 254.

HATTO, A. The Nibelungenlied: 2. Ed. Penguin Classics: Londres, 1969.

HOLLANDER, L.M. The Poetic Edda: 1. Ed. Austin: University of Texas, 1928.

HOLLINRAKE, R. Conclusão: a metamorfose final. In: HOLLINRAKE, R. Nietzsche, Wagner e a filosofia do pessimismo. Rio de Janeiro: Jorge Zahar Editor, 1994, p.198-229.

HOLLLINRAKE, R. Panorama intelectual: filosofia. In: MILLINGTON, B. [Organizador]. Wagner:um compêndio: Guia completo da música e da vida de Richard Wagner. Rio de Janeiro: Jorge Zahar Editor, 1995, p.62.

LARGE, D. A receptividade da obra: Alemanha. In: MILLINGTON, B. [Organizador]. Wagner:um compêndio: Guia completo da música e da vida de Richard Wagner. Rio de Janeiro: Jorge Zahar Editor, 1995, p.456-457.

MILLINGTON, B., Opiniões e perspectivas: Wagner e os judeus. In: MILLINGTON, B. [Organizador]. Wagner: um compêndio: Guia completo da música e da vida de Richard Wagner. Rio de Janeiro: Jorge Zahar Editor, 1995, p. 181-185.

NIETZSCHE, Friedrich. Wagner em Bayreuth. Rio de Janeiro: Jorge Zahar Editora, 2009. 


\section{ensaios}

Jaqueline Uzai Tavares

PORTER, A. [Tradução e Introdução]; WAGNER, R. O Anel dos Nibelungo: 1. ed. Londres: Faber Music Lta, 1976.

ROSS, Alex. The Ring and the Rings. Nova York, 2003. Disponível em: https://www.newyorker.com/magazine/2003/12/22/the-ring-and-the-rings. Acesso em: 24/01/2019.

STURMA, D. Politics and the New Mythology. In: AMERIKS, K. [Organizador]. The Cambridge Companion to German Idealism. Cambridge: Cambridge University Press, 2008, p. 219-238.

WHITTALL, A., O Impacto de Wagner na história da música. In: MILLINGTON, B. [Organizador]. Wagner:um compêndio: Guia completo da música e da vida de Richard Wagner. Rio de Janeiro: Jorge Zahar Editor, 1995, p. 461- 462. 